Florida International University FIU Digital Commons

FIU Electronic Theses and Dissertations

University Graduate School

9-2-1994

\title{
Memory for contingent versus noncontingent events
}

Maricel Cigales

Florida International University

DOI: 10.25148 /etd.FI14060836

Follow this and additional works at: https://digitalcommons.fiu.edu/etd

Part of the Child Psychology Commons

\section{Recommended Citation}

Cigales, Maricel, "Memory for contingent versus noncontingent events" (1994). FIU Electronic Theses and Dissertations. 2366.

https://digitalcommons.fiu.edu/etd/2366

This work is brought to you for free and open access by the University Graduate School at FIU Digital Commons. It has been accepted for inclusion in FIU Electronic Theses and Dissertations by an authorized administrator of FIU Digital Commons. For more information, please contact dcc@fiu.edu. 
FLORIDA INTERNATIONAL UNIVERSITY

Miami, Florida

Memory for Contingent Versus Noncontingent Events

A thesis submitted in partial satisfaction of the requirements for the degree of

MASTER OF SCIENCE

IN

PSYCHOLOGY

by

Maricel Cigales

1994 
To: Dean Arthur W. Herriott

College of Arts and Sciences

This thesis, written by Maricel cigales, and entitled Memory for Contingent Versus Noncontingent Events, having been approved in respect to style and intellectual content, is referred to you for judgement.

We have read this thesis and recommend that it be approved.

Scott Fraser

Mary Levitt

Lorraine Bahrick, Major Professor

Date of Defense: September 2, 1994

The thesis of Maricel Cigales is approved.

Dean Arthur w. Herriott College of Arts and Sciences

Dr. Richard L. Campbell

Dean of Graduate Studies

Florida International University, 1994 
This thesis is dedicated to my parents. To my mother who shares my accomplishment in spirit and my father who always encouraged me to strive for excellence. 


\section{ACKNOWLEDGMENTS}

My sincere gratitude to all of those who made the completion of this thesis possible. To Ted for his patience and support and my family for their love and encouragement.

Special appreciation to Dr. Bahrick, for her guidance and wisdom throughout this project and to Dr. Levitt and Dr. Fraser for their time and suggestions.

Many thanks to the students at the Infant Development Laboratory who helped carry out this project, especially Maria Hernandez-Reif who is a great motivator and friend. Finally, thank you to all of the parents and their infants who participated in this project. 


\section{ABSTRACT OF THE THESIS}

MEMORY FOR CONTINGENT VERSUS NONCONTINGENT EVENTS

by

Maricel Cigales

Florida International University, 1994

Miami, Florida

Professor Lorraine Bahrick, Major Professor

Twenty-four 7.5- to 8-month old infants were presented with two manipulanda and given either behavior-contingent or noncontingent experience with an object. Infants in the contingent group learned and remembered the controling action for up to 1 week $(\underline{t}(11)=2.83, \underline{p}<.05)$, whereas those in the noncontingent group showed no preference for either action. There was no evidence of memory, however, for the familiar object by either group. This surprising finding may be a result of greater interest in the action than in the object. 
I. INTRODUCTION $\ldots \ldots \ldots \ldots \ldots \ldots \ldots \ldots \ldots \ldots \ldots \ldots$

II. LITERATURE REVIEW $\ldots \ldots \ldots \ldots \ldots \ldots \ldots \ldots \ldots \ldots$

Affective Responses to Contingencies .......... 3

Contingency Perception ................. 10

Visual Contiguity and Contingency Perception ..... 13

Schedules of Reinforcement and

Contingency Learning ................ 18

Memory for Contingencies .............. 23

Learning Contingencies Via Imitation .......... 29

III. SUMMARY OF THE LITERATURE $\ldots \ldots \ldots \ldots \ldots \ldots \ldots \ldots$

IV. METHODOLOGY ...................... 43

Subjects ..................... 48

Stimulus Materials .................. 49

Apparatus ........................ 51

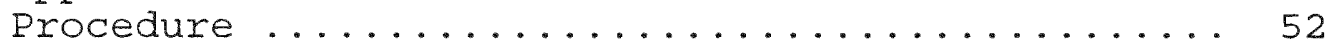

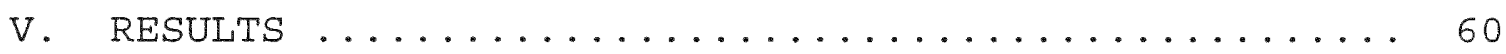

Memory for the object ................ 60

Memory for the Action ....................6 63

Interobserver Reliability .............. 67

Data from Dropped and Attrition Subjects........ 68

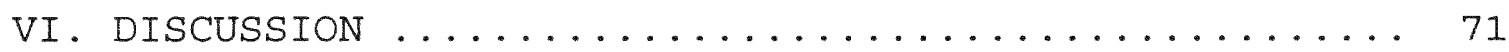

LIST OF REFERENCES $\ldots \ldots \ldots \ldots \ldots \ldots \ldots \ldots \ldots \ldots \ldots \ldots \ldots \ldots \ldots \ldots$ 
List of Figures and Tables

Figure

1. Red, blue and yellow stimulus objects, from

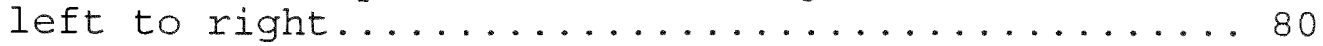

2. Apparatus from the infant's perspective........ 81

Table

1. Between- and within-subjects independent variables and levels................... 82

2. Complete counterbalancing of between-subjects independent variables and levels $(\mathrm{N}=24) \ldots \ldots 83$

3. Means and standard deviations for subjects in both conditions across time $(\mathrm{N}=24) \ldots \ldots . .84$

4. ANOVA and t-test results for PTA and difference scores......................... 85

5. Pearson product moment correlations of primary and secondary observer PTA scores across phases......................... 86

6. PTLT scores on memory for the object tests for subjects who were dropped from the experiment

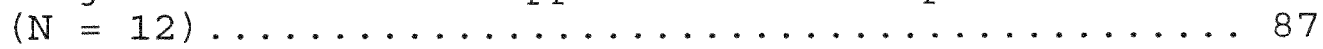

7. PTA scores across phases for subjects who were dropped from the experiment $(N=12) \ldots \ldots \ldots . \ldots 88$

8. Mean PTLT scores on the first memory for object test for the final sample and attrition subjects $(N=35) \ldots \ldots \ldots \ldots \ldots \ldots \ldots \ldots . \ldots . \ldots . \ldots$ 


\section{Chapter I}

\section{INTRODUCTION}

Contingency awareness by human infants was originally investigated by John S. Watson. Watson (1966) proposed that contingency awareness is a necessary condition for learning, and that human infants are born with the adaptive ability to perceive contingencies. Since Watson's seminal article, many researchers have investigated the role of contingency perception in infant development. This paper provides an overview of the contingency literature and presents findings from a recent research project on infants' memory for contingencies.

Chapter 2 begins with an overview of infants' affective responses to contingencies, followed by a description of several studies that demonstrate the young infant's ability to detect and learn behavior-contingent relationships. The literature review then turns to the matter of how infants learn behavior-contingent relationships. Two primary areas of research are addressed in answering these questions, visual contiguity of contingent stimuli and schedules of reinforcement. Next, the literature on memory for contingencies is reviewed. Though limited in scope, this literature indicates that infants have the ability to remember behavior-contingent relationships over extended periods of time. Finally, several studies are reviewed that 
indicate that infants can learn behavior-contingent relationships via imitation. The literature is then summarized in Chapter 3, and the thesis of the current research project is introduced.

Chapter 4 presents the theoretical rationale for the current research project, followed by the methodology. Consistent with Watson's position, this thesis maintains that contingency perception is ethologically significant and thus is crucial to normal infant development. The results of the study are presented in Chapter 5. Finally, Chapter 6 integrates the current findings with the existing literature and suggests new directions for research. 
Chapter II

\section{LITERATURE REVIEW}

Cause-and-effect events surround the infant daily. Most cause-and-effect events occur independent of the infant's behavior and will be inconsequential for him/her. Other events may be contingent on the infant's behavior, and theix outcomes may be important to the infant's adaptation in his/her environment. It seems logically adaptive then for the infant to learn which events he/she can control and how. For example, an infant will cry when experiencing discomfort or hunger, alerting his mother that something is wrong. As language is acquired, children learn that specific words often produce the fulfillment of certain needs. Imagine the fate of an organism who is incapable of learning and remembering response-contingent relationships. This organism would likely have difficulty adapting to its environment.

\section{Affective Responses to Contingencies}

Mineka, Gunnar and Champoux (1986) demonstrated the importance of having control over one's environment in a study with rhesus monkeys. Results showed that "master" monkeys, who could control the delivery of food, water, and treats, displayed less fear and more exploratory behavior of a mechanical toy than did monkeys who received edibles noncontingently. These results are supported by Mason (1978) 
who reported that using dogs as surrogates for rhesus monkeys was less detrimental than inanimate surrogates. The author suggests that amelioration of detrimental effects may be attributed to response-contingent stimulation provided by surrogate dogs.

Similar results have been shown in 12-to 13-month-old infants (Gunnar-Vongnechten, 1978). Control over a potentially frightening toy reduced fear responses in male subjects and increased positive affect in male and female subjects. Half of the 24 male and 24 female subjects were randomly assigned to a controlling condition or a noncontrolling condition. The potentially-frightening stimulus was a mechanical cymbal-clapping monkey. Infants in the controlling condition were trained during a familiarization phase to hit a panel on a tray before them in order to activate a toy merry-go-round. Infants in the noncontrolling condition experienced similar familiarization with the toy merry-go-round, but were not trained with the panel. During the test phase the merry-go-round was replaced by the monkey. Each group was then exposed to the monkey under its respective condition. Controlling infants were able to activate the monkey at will while noncontrolling infants had no control. Subjects in the noncontrolling condition were yoked to subjects in the controlling condition in order to equate groups on the 
number of stimulus activations. Thus, each noncontrolling infant received the same number of stimulus activations, at the same intervals, as were generated by the previous controlling infant. Measures of positive affect responses, proximity to the toy and touching the toy, as well as the number of toy activations for controlling infants, provided an index of the infants' positive responses to the stimulus. Fright was indexed by fussing and crying, support looks to the mother and closeness to the mother. Results indicated that infants in the controlling group responded significantly more positively to the monkey, as indexed by smiling, laughing and approaching, than did noncontrolling infants. However, only the male infants showed significantly greater amounts of negative affect in the noncontrolling condition than in the controlling condition. It was concluded that reaction of 1 -year-olds to an arousing event is a function of their control over it. Thus, having no control produced fearful (for males), or at least neutral (for females), responses, while control produced positive responses for both males and females. This study indicates that even a potentially distressing event can produce a positive affective outcome in infants when it is contingent upon their behavior.

Lewis, Sullivan and Brooks-Gunn (1985) found parallel results in 10-, 16- and 24-week-olds under a contingent 
reinforcement condition. Subjects were assigned to either a contingent condition, in which arm movements were reinforced with audio-visual stimuli, or a noncontingent control group. For infants in both groups, sessions lasted as long as they remained interested and did not fuss or cry. Affective measures showed that subjects in the contingent condition had longer sessions and fussed/cried less than did the noncontingent control subjects. Subjects at 16 and 24 weeks of age also smiled more under contingent stimulation than noncontingent controls of the same age. Interestingly, the fuss/cry response decreased with age for contingent subjects and increased with age for noncontingent subjects. Based on these results, the authors suggest that contingent stimulation may produce a child who is more involved and interested in the environment, which may in turn promote subsequent competence. Speculation aside, this study indicates that contingent stimulation contributes to longer task involvement and promotes positive affect. Age differences on affective measures indicated that the effects of contingent versus noncontingent stimulation intensified from 10 to 24 weeks of age.

Watson and Ramey (1969 in Watson, 1971) also found an increase in positive affect in 2 -month-old infants under conditions of response-contingent reinforcement. Subjects in the experimental group could cause a mobile, suspended 
above their cribs, to turn for one second by making head movements against a pressure-sensitive pillow. Control subjects were exposed to either a noncontingently moving mobile or one that remained stabile. Subjects in all conditions were exposed to the stimuli for 10 minutes each day over a 14-day period. Results showed that experimental subjects significantly increased backward head movements while control subjects did not, indicating that experimental subjects learned that they could control the mobile. Additionally, experimental subjects displayed vigorous smiling and cooing toward the mobiles after the third day of exposure to the contingent reinforcement. This socioemotional response was not displayed by infants in the control groups. These results indicate that contingency perception is often accompanied by positive affect.

Gunnar (1980) compared the effects of predictability and control on infants' responses to an arousing, fearprovoking toy. Twelve-month-old infants were assigned to one of three conditions; controlling, predicting or noncontrolling. Infants in the controlling condition could simultaneously activate a potentially frightening toy and a bell. Infants in the predicting condition could not control the activation of the toy, but the bell always sounded first, thus acting as a predictor for the activation of the toy. Infants in the non-controlling condition had no 
control over the toy and were not provided with the warning bell. Affect was assessed by the frequency and intensity of fuss/cry and laugh/smile responses. Results showed that infants in the controlling condition approached the toy significantly more than did infants in either the predicting or noncontrolling conditions. Only infants in the controlling condition displayed little distress upon the toy being activated and they explored it more than did the other two groups. Infants in the predicting condition showed as much distress and as little exploration of the toy as did infants in the non-controlling condition. Thus, predictability did not significantly reduce negative responses to the toy's activation, while having control did. Finally, Levitt (1980) found that 10-month-old infants had more positive affective responses to a stranger if they could control the strangers initial appearance than if they could not. In Phase 1, subjects in the 'contingent' condition, could produced the appearance of the stranger from behind an occluder by touch a cylinder. In two 'noncontingent' conditions, the stranger appeared either frequently or infrequently, but her appearance was not controlled by the infant. The infant's affective responses were then recorded in a Phase 2 during a "stranger approach" procedure and a free-play situation. During Phase 1 only subjects in the contingent condition showed an increase in 
the frequency of touching the cylinder, indicating that they learned the behavior-contingent relationship. The results of Phase 2 indicated that infants in the contingent condition responded more positively (e.g., smiles, vocalizations and visual orientation) to the stranger when the stranger was at a distance and less negatively (e.g., crying, whimpering and postural or visual avoidance) when the stranger was near than subjects in the two noncontingent conditions. Infants in the contingent condition were also more tolerant of the stranger's intrusions than infants in the other two groups. Levitt (1985) suggests that contingent experience may mediate the development of social relationships.

The studies cited above suggest that infants prefer situations which they can control. Results indicate that control over an event is comforting and promotes exploratory behavior more than uncontrollable events. Because control reduces negative affect, as well as promoting positive affect and interaction with stimuli in the environment, it might therefore facilitate learning. It seems reasonable to propose that the ability to detect contingencies, particularly as they relate to our own behavior, is an adaptive skill. Thus, learning which situations are contingent upon our behavior and which are not may be important for survival. At a minimum, it would allow us to 
manipulate our environment in a way that would maximize the occurrence of positive events and minimize negative ones.

The above studies point to the importance of examining the dynamics of contingency perception in infants. Perhaps by determining what properties specify contingencies we can better understand how infants are able to perceive their control over contingent events.

The remainder of this review will provide evidence for which contingent relationships infants are capable of perceiving and what factors contribute to or inhibit this process. Furthermore, it will provide an understanding of how infants learn they have control over contingent events. Contingency Perception

Watson (1967) showed that the visual fixation behavior of 14-week-olds could be influenced by contingent reinforcement. Infants were placed face-up in a bassinet with a black ceiling containing two translucent circles, located laterally to the infants' right and left. Infants could control discrete reinforcements, which consisted of a tone or lighting of the target circle, by fixating on the appropriate circle. Infants showed a significant increase in the rate of visual fixation on the designated circle. This demonstrates that 14-week-old infants can learn that performing a particular response will produce a reinforcing stimulus. 
Watson and Ramey (1969, in Watson 1971) also found that infants as young as 8 weeks of age can learn to control the movement of a mechanical mobile suspended above their crib. The 2-month-old infants were exposed to the mobile for 10 minutes per day, for two weeks. The infants in a contingent condition could cause the mobile to turn for one second by applying backward head pressure to a pressure-sensitive pillow. Results showed that infants who could control the mobile increased their response rate significantly above baseline levels across the two-week period, while infants who had no control did not.

These studies with 8 - and 14 -week-old subjects show that infants can perceive contingent relationships at a very young age. Also, once a contingency is learned, infants tend to engage in the controlling behavior at a higher rate than they would when the contingent relationship does not exist.

Rovee and Rovee (1969) used a conjugate reinforcement paradigm to test 9 - to 12 -week-old infants' exploratory behavior. Under conjugate reinforcement infants were able to control the frequency, duration and intensity of the motion of a mobile (which was suspended above their cribs) via a cord connecting the mobile to one of their feet. For example, if the infant kicked his/her foot vigorously three times in five seconds, the mobile would shake vigorously 
three times in five seconds. This differs from the discrete reinforcement employed by Watson in that infants can only control frequency of reinforcement under discrete conditions. Thus, conjugate reinforcement provides immediate stimulus feedback that is congruent to the target behavior.

The paradigm used by Rovee and Rovee (1969) consisted of a training session composed of three phases; 1) a 27-minute baseline period in which the operant level of foot-kicking is established, 2) a 15-minute acquisition phase with conjugate reinforcement, 3) a 5-minute extinction phase. The phases were separated by 2 -minute intervals. Results showed that infants in the conjugate reinforcement condition increased their response rate threefold after three minutes of conjugate reinforcement. Subjects in a noncontingent, but otherwise identical condition (in which an experimenter moved the mobile), showed no increase in foot-kicking rate. This indicates that infants have memory for contingent events and will choose to produce events when given the opportunity. Furthermore, the dramatic increase in footkicking rate by subjects who received conjugate reinforcement suggests that contingent events are highly rewarding.

The above research on contingency perception has focused on whether infants perceive and learn contingent 
relationships. A more intriguing and implied question is how do infants know they have control; what cognitive mechanisms might be at work in cuing the infant? One answer to this question is temporal contiguity. The literature suggests that infants come to perceive their control over an event when they have repeatedly experienced that event following a particular behavior (Watson, 1972 \& 1967; Rovee \& Rovee, 1969). This implies, simply, that infants learn that when they do $R, S$ will happen. However, studies discussed below will show that temporal contiguity is a necessary but not sufficient component for responsecontingent connections to be made by infants. Other factors contribute to the infants' ability to learn that a contingent relationship exists between an event and their behavior, as well as to identify the particular target behavior. These factors, discussed below, include visual contiguity and schedule of reinforcement.

Visual Contiguity and Contingency Perception

Visual displacement of stimuli, relative to the infant's line of sight, is a second factor which influences contingency perception. Studies in this area provide further explanation of how contingency perception might develop.

Millar and Schaffer (1972) studied the effects of visual discontiguity between an operantly activated stimulus and 
the controlling manipulandum on contingency perception in 6, 9- and 12-month-old infants. A perforated canister served as the manipulandum in three conditions. The canister was placed before the subjects. By touching the canister the infants could activate the stimuli under conditions of 0,5 , or 60 degrees of lateral displacement. In the zero displacement group, colored lights and tones emanated from inside the canister upon activation. In the two displacement groups, the audio-visual stimulus was emitted by a duplicate canister that was displaced either 5 or 60 degrees from the manipulated canister.

Results showed that 6 -month-old infants were unable to learn the task when the response contingent stimulus was displaced 60 degrees from the manipulandum, just outside of the infants' visual field. However, with only 5 or 0 degrees of visual displacement, where both the manipulandum and the feedback stimulus were within the visual field, 6month-olds successfully learned the contingency. Nine- and 12-month-olds were able to learn under 0-, 5- and 60-degree displacement conditions. Thus, 6-month-olds seem to require visual contiguity between a stimulus and its controlling manipulandum in order to detect a contingency and learn an operant task. By 9 months of age, infants are able to learn contingencies despite such visual discontiguity. This indicates a broadening of contingency perception with age. 
Cavanagh and Davidson (1977) also found that 6-montholds were unable to acquire an operant response when the visual component of a contingent audio-visual stimulus was displaced. In this study a colored light display and a tone were located directly behind a clear plexiglass panel, which served as the manipulandum for infants in a nondisplacement condition. In the second condition the visual component of the stimulus was displaced 60 degrees to the left of the panel. Infants in the non-displacement condition were able to learn the contingency while infants in the 60-degree displacement group could not.

One caution should be noted when interpreting the results of this study. The audio component of the stimulus was located directly above the infants in all conditions. This was done to cue the infants to the visual stimulus, which was directly in front of them during the contiguous condition. It is possible that in the 60-degree visual displacement condition the audio cue confused or misoriented the infants, thereby confounding the results by producing competing tendencies to look in two directions at once.

However, Millar (1985) found the same results in a study with 6- and 12-month-olds. In this study the audio and visual components were contained within the feedback stimulus, thus they were jointly displaced. Again, 6-montholds were unable to learn a contingency under a 60-degree 
visual displacement condition, while 12-month-olds acquired the operant response.

Another study by Millar (1974) lends support to the idea that 6-month-olds' inability to learn under a 60-degree displacement condition may be associated with their memory system. In this study, the manipulandum was directly in line with a translucent screen, behind which was a set of lights. Touching the screen caused the lights to turn on. Thus, the lights were only visible while they were providing immediate feedback. In the "cue-assisted" condition a plastic ring circumscribed the area where the feedback would occur. In the "no-cue" condition the plastic ring was not present, thus there was nothing marking the area where the lights were. Results showed that 9-month-olds learned the contingency under both conditions while 6-month-olds learned only under the cued condition. The authors concluded that 6-month-olds need a "visual holding cue" during the interresponse interval in order to learn the contingency. Thus, visual contiguity between the manipulandum and the feedback source appears to be an important factor in contingency perception in infants up to 6 months of age.

Results generated by 9 - and 12 -month-olds suggest at least two possible explanations for why 6-month-olds may not be successful at contingency perception in the absence of visual contiguity. First, this research suggests that 
displacement of the response-contingent stimulus outside of the visual field may impose greater demands on the infant's information storage and recall system. In order for an infant to learn the relationship between manipulating an object before him and the subsequent activation of a stimulus outside of his field of vision, the infant must do two things; 1) While looking at the manipulandum he must store some type of information about the feedback stimulus and be able to recall it in order to remember to turn towards it for reinforcement upon making the operant response; 2) While focusing on the feedback stimulus, the infant must store information about the manipulandum and be able to recall that it is the means through which he/she can reactivate the stimulus. It is possible that 6-month-olds' memory storage and retrieval systems are not sufficiently developed to facilitate this process, while that of 9 - and 12-month-olds are sufficiently advanced. This explanation, however, seem unlikely.

A second possibility is that of differential attention strategies between the two age groups. Millar and schaffer (1973) observed that 9-month-olds tended to focus on the feedback stimulus while continuing to touch the manipulandum. This behavior was not typical of the 6-montholds. Consequently, 6-month-olds may not attend to the stimulus and manipulandum simultaneously, preventing them 
from learning the contingency.

To summarize, research supports the notion that for infants as old as 6 months of age, visual contiguity between stimulus and manipulandum is necessary for acquisition of an operant response in a contingency task. However, at least one study (Millar, 1974) suggests that visual holding cues, in the absence of visual contiguity, can facilitate response acquisition in 6-month-olds. By 9 months of age infants are able to overcome the difficulties of a 60-degree displacement of the contingent stimulus either through a more developed memory system or more effective attention strategies.

Schedules of Reinforcement and Contingency Learning

Another factor which influences the learning of a contingent relationship is the rate and schedule at which infants' responses are reinforced. Watson (1972) presented 2-month-old infants with contingent and noncontingent discrete reinforcements across a 14 -day period when they produced foot motions of sufficient intensity to activate a pressure-sensitive pillow. The infants experienced two 10minute sessions daily; one session was run under the contingent condition and the other under the noncontingent condition. This procedure produced an initial increase in activity and response rate followed by a progressive decline in both across contingent and noncontingent sessions. 
Results suggest that alternating contingent and noncontingent reinforcement interferes with contingency perception.

Watson further explored the effects of partial reinforcement on contingency perception in another experiment. Reinforcement was provided either 40 percent or 60 percent of the time contingent on infants' backward head pressure to their pillow. Results showed that under neither condition did 8-week-old infants learn the contingent relationship between their behavior and the mobile's movement. Thus, 8-week-old infants need a rate of reinforcement higher than 60 percent in order to learn a behavior-contingent relationship. Unfortunately, this study did not pinpoint the minimum rate of reinforcement necessary for 8-week-olds to learn a contingency.

Interestingly, watson (1979) found that reinforcement of behaviors that occur at extremely high rates can also interfere with an infant's ability to perceive contingencies. Eight-week-old infants were exposed to a response-contingent mobile reinforcer for 10 minutes per day, for seven days. Pressure-sensitive pillows were placed under subjects' legs so that sufficient leg movement would cause the mobile to turn for one second. Two groups received identical conditions. However, the pillows were differentially calibrated so that the one used in group $B$ 
was twice as sensitive to pressure as the one used in group A. Group A showed a steady increase in response rate and smiling behavior over the seven-day period, relative to baseline. However, group B showed no increase in response rate or smiling over that same period. These results suggest that reinforcement of the higher frequency behavior hindered infants' ability to learn the contingency. This is consistent with watson's proposal that the probability that a subject will respond is greater at lower contingency magnitudes as compared to extremely high magnitudes (Watson, 1979). One reason for this may be that when an event is contingent upon a very frequent behavior, it is likely that other behaviors will occur simultaneously. Thus, infants may not be able to isolate the controlling behavior.

Millar and Watson (1979) studied the effects of delayed reinforcement on contingency behavior in 6-to 8-month-old infants. Infants' wide arm movements were audio-visually reinforced with lights and tones under one of four conditions, immediate reinforcement, 3-, 6-, or 10-second delayed reinforcement. In all groups delayed feedback failed to produce a significant increase in responding relative to baseline measures. Infants in the immediate reinforcement group were able to learn the contingency and significantly increased their response rates above baseline measure. 
However, Reeve, Reeve, Brown, Brown and Poulson (1992) were able to successfully train three 4- to 6-month-old infants to learn a behavior-contingent relationship using a multiple-baseline across subjects design. The 12-minute conditioning sessions took place three or four times per week over a three month period. During the sessions, each infant was seated facing a panel with a window shade. The infant's mother was seated behind the shade. The mother's appearance was contingent on infant vocalizations. Baseline levels of vocalizations were first assessed. Following baseline subjects experienced an alternating DRO and delayed reinforcement phases. DRO consisted of providing immediate reinforcement of infant behaviors other than vocalizations with the appearance of the mother. The first phase after baseline was a DRO phase for all three subjects. The delayed reinforcement phases consisted of reinforcing infant vocalizations with the appearance of the mother only after a 3-second delay. The data revealed that all three infants showed consistently higher rates of vocalizations during the delayed reinforcement phases than during the DRO phases. These findings suggest that with sufficient training infants can learn a behavior-contingent relationship despite a three-second delay of reinforcement.

These studies point out several factors that are important in contingency perception. First, if an event is 
alternately contingent and noncontingent, it tends to interfere with contingency perception. Though infants might initially detect the relationship over repeated exposure to the inconsistent event, their response rate declines. Also, reinforcement rates of 60 percent or less prevent 2 -montholds from perceiving the contingency between their behavior and a subsequent event. A third important finding addressed the effect of delayed reinforcement on contingency perception. Six- to 8-month-old infants have been shown to be unable to detect contingencies if the contingent reinforcement is delayed by three or more seconds. Perhaps during initial learning, memory for the feedback-producing behavior is limited to less than three seconds. One possibility is that intervening behaviors inhibit infants' ability to associate the controlling behavior with the contingent event if there is a delay of three or more seconds. However, with extensive operant training, 4- to 6month-old infants can overcome a three-second delay condition and learn the behavior-contingent relationship.

Finally, very high rates of contingent stimulation has also been found to inhibit contingency perception in infants. This finding suggests that when high frequency behaviors are reinforced, infants are unable to perceive the relationship between their behavior and the contingent event. Perhaps, this is because the event seems to occur by 
chance, since they cannot isolate the controlling response. Memory for Contingencies

Though the developmental literature is replete with studies of infants' memory for features of objects, very few have addressed infants' memory for events. Fewer still have investigated infants' memory for contingent relationships over time. There is, however, one group of studies that have simultaneously addressed infants' memory for events and their precipitating contingencies. The conjugate reinforcement paradigm (Rovee and Fagen, 1976) was used in these studies and has yielded robust measures of infant memory.

The conjugate reinforcement paradigm uses foot-kicks as the dependent variable. It consists of two training sessions 24 hours apart, and a third session, that assesses long-term memory, can occur at any interval after session two. Each training session includes, 1) A three-minute baseline period, to establish each infant's natural footkicking rate; 2) A nine-minute acquisition phase, in which the infant can control the motion of a suspended mobile via a cord connecting the infant's foot to the mobile; 3) A three-minute extinction phase, in which the infant cannot control the mobile. The phases are one minute apart. Footkicks are recorded during each phase of both sessions. The baseline phase of session two is compared to the 
extinction phase of session one to measure the infant's retention of the contingency across the 24 -hour retention interval. The measured decrease in kicking from session one, extinction to session two, baseline is an index of forgetting. Memory over a retention interval of more than 24 hours is assessed by comparing baseline of session three to extinction of session two (Rovee-Collier and Fagen, 1981).

Sullivan, Rovee-Collier and Tynes (1979) employed this paradigm to investigate long-term memory for a responsecontingent relationship in 3-month-olds. Subjects received two training sessions, 24 hours apart. A third occurred either 96, 144, 192, or 336 hours later, according to each subject's condition. Subjects showed nearly perfect retention from session one to session two and demonstrated long-term retention up to 192 hours, as indicated by no significant decrease in response rate from session two, phase three to session three, phase one. Only after an interval of 336 hours (14 days) did infants show significant forgetting (i.e., a significant decrease in response rate) as indexed by foot-kicking rate comparisons.

Forgetting and memory retrieval in 2 -month-olds was further investigated by Greco, Rovee-Collier, Hayne, Griesler and Earley (1986). After two training sessions, subjects received a retention interval of $1,3,6$ or 9 days. 
Response rate was the dependant variable indicating forgetting. Two-month-olds showed complete forgetting after a retention interval of more than one day, but showed memory at one day. That is, after retention intervals of more than one day, 2-month-olds showed no increase response rates above baseline levels during the long-term memory test.

In a second experiment, researchers reactivated memory in 2- and 3-month-olds after complete forgetting had occurred in both groups. Reactivation occurred 24 hours prior to the long-term memory test and consisted of showing the infants the same mobile used in the training sessions for three minutes, during which the mobile moved noncontingently. Researchers indexed the differential contribution of the infants' age and the age of the memory to retrieval abilities. Infants were tested at 28 and 35 days, following training, using the same long-term memory test procedure as above in order to explore the limits of memory reactivation. Results showed that reactivation was successful at 28 days, but not 35 days, for the 3 -month-old group only. Two-month-olds showed no memory reactivation after 28-or 35-day retention intervals. Memory reactivation in two-month-olds is apparently limited to an 18-day retention interval, as demonstrated by Davis and Rovee-Collier (1983) using the same procedure. Long-term reactivation results indicated that retrieval was impaired 
by the amount of time that passed between the onset of forgetting and the presentation of the reminder. In the 28day retention interval condition, the reminder was given on the 27th day. Thus, for 2-month-olds (who show complete forgetting after 24 hours) 26 days elapsed between forgetting and the reminder. For 3-month-olds (who forgot after 14 days) only 13 days passed since forgetting occurred.

In summary, infants' ability to access memory for a contingent relationship is a function of the amount of time that has elapsed since the "onset of forgetting." Twomonth-olds show complete forgetting after periods of more than one day, while in 3-month-olds memory persists up to eight days. Retrieval cues successfully reactivate memory in 2-month-olds after a 18-day retention interval and in 3month-olds after as long as 28 days.

Retrieval is also impeded if reactivation cues are sufficiently discrepant from the training stimulus (RoveeCollier, Patterson \& Hayne, 1985). Though infants' memory can be reactivated after forgetting has occurred, substituting more than one component of the five-component training mobile with a novel component produced ineffective reactivation in 3-month-olds in a two-week long-term retention test. The same effects have been found with 2month-olds after a retention interval of only 24 hours 
(Hayne, Greco, Earley, Griesler \& Rovee-Collier, 1986).

The duration and distribution of contingent experience can also determine infants' abilities to remember contingencies. In a study with 2 -month-olds (Linde, Morrongiello \& Rovee-Collier, 1985), researchers exposed infants to two sessions, either one week or two weeks apart, using the conjugate reinforcement paradigm. Training phases varied in duration such that infants received either 6,12 , or 18 minutes of contingent experience. Only infants who received 18 minutes of training were able to remember the contingency two weeks later. In a second condition, training duration was held constant at 18 minutes, and was either distributed across three 6-minute training sessions or was provided in one 18-minute training session. The results showed that only the infant who received the distributed contingent experience were able to recall the contingency two weeks later.

Finally, both 2- and 3-month-olds show response rates significantly below baseline levels in a 24 -hour retention test when more than one novel component is substituted in the mobile. These results indicate that 2 - and 3-month-old infants are capable of encoding specific information about the mobile during training and can detect discrepancies in its components from the training to the reactivation phase. Researchers studying contingency perception in infants 
have focused primarily on identifying the temporal and spatial limits of this ability. Several studies have investigated the effects of visual displacement of stimuli (Cavanagh \& Davidson, 1977; Millar \& Schaffer, 1972, 1973; \& Millar, 1974, 1975) and rates of contingent reinforcement (Watson, 1972 \& 1979; Millar \& Watson, 1979) on infants' ability to perceive and learn relationships which are contingent on their behavior. However, there is no research designed to determine how contingency perception in infants is affected when an event is contingent on another person's behavior and how this may affect memory. For example, the conjugate reinforcement paradigm has shown that an infant can learn the contingency between kicking his/her leg and the motion of a mobile suspended above his/her crib, as indicated by a significant increase in response rate above baseline. Furthermore, memory for this contingent relationship persists for eight days by 3 months of age. However, if the same subject were to observe another person causing the mobile to move in the same manner, would he/she still be able to detect the contingency? If so, would memory for the contingency last as long as it would if he/she had controlled the mobile him/herself? These questions are unanswered in the current literature. Nevertheless, insight may be gained from literature found under the headings of imitation and observational learning. 
Learning Contingencies Via Imitation

Certainly many contingent relations that an infant may be exposed to are not contingent on the infant's own behavior. For example, when mom flicks the light switch when leaving a room, the light turns off. When dad winds-up the bath tub toy it paddles around the tub. These types of experiences with contingent relations, though once removed from the infant's own behavior, are nonetheless a potential source of learning about actions and objects in the environment. Thus, another factor that may determine whether an infant can learn and remember a contingent relationship is if the contingency is dependent on his/her own behavior or that of another person. No research to date, however, has directly addressed this issue.

If young infants can learn other-dependent contingent relations, a prerequisite for this skill would likely be the ability to learn object-action relations via observation. While there is no literature on observational learning by infants, the imitation literature indicates that infants can learn and remember object-action relationships by observing the behaviors of others.

Meltzoff (1985) studied 14- and 24-month-olds' ability to imitate a simple action on a novel toy under immediate and 24-hour deferred conditions. Subjects were randomly assigned to the two conditions. Within each group subjects 
were assigned to one of three test conditions. In the "imitation" condition an experimenter modeled a target behavior, pulling the toy apart and reassembling it. This was done three times in one 20 -second presentation period. In the "baseline" condition the toy was shown to the subjects for 20 seconds, but the target behavior was not modeled. This condition controlled for spontaneous production of the target behavior. In the "activitycontrol" condition an experimenter modeled a behavior that was different from the target behavior three times in 20 seconds. This condition controlled for the possibility that subjects might be more motivated to manipulate a toy if they observed an adult touch it, and might thus have a greater tendency to produce the target behavior. Following presentations, all subjects were given a 20 -second response period either immediately or 24 hours later. During this period observers scored whether or not subjects pulled the toy apart and measured the latency of the response if it was produced. Strong evidence for imitation was obtained only for infants in the imitation test condition on immediate and 24-hour delayed tests. A significantly high percentage of 12- and 14-month-old infants in the imitation condition, as compared with the two control conditions, displayed the target behavior on immediate and 24-hour delayed tests. Subjects in the imitation condition had lower mean latency 
scores than subjects in the two control conditions. These results were consistent across age and deferred groups. Furthermore, there were no significant differences between subjects in immediate and deferred imitation groups. This study indicated that infants as young as 14 months of age were able to recall and reproduce target behaviors immediately and 24 hours after observing the behavior. Meltzoff suggests that imitation may thereby play a role in learning and socialization during infancy.

Meltzoff (1988a) investigated the ability of 9-montholds to imitate actions on novel objects under immediate and 24-hour delay conditions. Infants in immediate and 24-hour delay groups were shown a series of three target actions on three novel test objects. Each action was demonstrated three times during a 20-second modeling period before moving on to the next action and object. Following this, half of the subjects were given an immediate imitation test and half were given the same test 24 hours later. Subjects were presented the same objects, one at a time, in their original sequence. Subjects were allowed a series of three 20-second response periods, starting from the subjects' first touch of the object. Three control groups were used. The "baseline" group did not experience the imitation periods. This group controlled for the probability of spontaneous production of the target action. The "adult-touching" group observed an 
adult hold the object during the modeling period but was not shown the target actions. This condition controlled for the possibility that subjects might be induced to produce the target actions by seeing an adult approach and touch the object. The "adult-manipulation" group observed adults perform actions on the object that were different from the target actions, but produced the same consequence (i.e. the object beeped or rattled). This group controlled for the possibility that infants who see that objects have consequences may be more motivated to perform actions on them.

Results indicated that 9 -month-old infants are capable of both immediate and 24-hour delayed imitation. Infants in both imitation groups produced significantly more target behaviors than control groups. The fact that 50 percent of infants in both the immediate and deferred imitation groups were assessed "high" imitation scores, meaning that they produced at least two of the three target behaviors, is particularly interesting. This suggests that the ability of 9-month-olds to imitate simple action on novel objects is persistent across a delay of 24 hours. Furthermore, the task in this study was more difficult and can be considered to require more memory than the task in the previous Meltzoff (1985) study. Meltzoff (1985) required that subjects recall only one action-object pairing, while there were three 
action-object pairings in the Meltzoff (1988a) study. Thus, subjects in the latter study had more information to process and recall on the test and potentially had interference from one task to the next.

However, caution should be exercised when comparing the results of the above two studies. The results of the Meltzoff (1985) study showed that infants as young as 14 months of age were able to imitate novel actions on objects. Meltzoff (1988a) extended these findings to 9-month-olds. However, the tasks were different in the two studies. The 1985 study tested subjects' ability to imitate a novel action on a familiar object. The 1988a study tested 9month-olds' ability to perform familiar actions on novel objects. Thus, direct comparisons cannot be drawn between these two studies. It may be, for example, that at nine months of age objects are more salient to infants than actions. Thus, performing a familiar action on a novel object may be easier than performing a novel action on a familiar object for 9-month-old infants. If so, Meltzoff (1988a) may have made the task disproportionately easy for subjects when compared with Meltzoff (1985). An alternate hypothesis is that it is simply easier to imitate familiar actions than nonfamiliar actions. However, it is also important to note that the 9 -month-olds had to imitate three different actions on three different objects, while 14-and 
24-month-olds had to imitate only one novel action on one object. Thus, the task for 9-month-olds may have required more memory than did the task required of 14 - and 24 -montholds. The results of the 9 -month-olds are, thus, very robust, particularly since they were successful at the task even after a 24-hour delay.

Meltzoff (1988d) used the same procedure to investigate 14-month-olds' ability to imitate novel actions and to defer imitation up to one week. Infants were shown a series of six objects and their corresponding actions. One of the actions was novel and consisted of touching a box with one's forehead in order to make a light come on inside. The other five actions were familiar. The purpose of the novel action was to broaden the range of acts previously studied with 14month-olds to include novel actions. Results showed that infants in the imitation condition produced significantly more target behaviors than did subjects in the "baseline" or "adult-manipulation" control conditions after one week.

These studies by Meltzoff have important implications for infant memory. Results of the 9-month-olds (Meltzoff, 1988a) indicate that infants of this age are able to recognize objects after a 24 -hour retention interval, after only 20 seconds of familiarization. These infants were also able to recall object-action relationships after 24 hours, with only three exposures to the target behavior during the 
same 20-second familiarization period. By 14 months of age, infants were shown to recall novel actions after delays as long as one week. This indicates that infants as young as 9 months are able to learn object-action relationships via observation and that memory for these relationships is very robust.

A study by Abravanel, Levan-Goldschmidt and Stevenson (1976) indicated that actions on objects may be more salient to 6- to 18-month-old infants than actions without objects. A series of 22 actions were modeled for 6-, 9-, 12-, 15- and 18-month-olds. Thirteen of these were simple actions performed on common objects, three were actions without objects which the subjects could see themselves do le.g., pat-a-cake) and six were actions without objects which subjects could not see themselves do (e.g., open and close mouth). Subjects were given the opportunity to imitate each action immediately after it was modeled. A control group received no modeling, but were given each of the materials for the actions on objects for one minute and were observed for five minutes to assess spontaneous production of actions without objects. Results showed that subjects who received modeling produced the target action significantly more than did control subjects. There were significant increases in imitation across age for most actions between 9 and 12 months of age. Overall, however, actions on objects were 
imitated more than actions that subjects could not see themselves perform.

Abravanel and Gingold (1985) investigated deferred imitation in 12- and 18-month-olds on three types of "object-related actions." The actions were "single/simple tasks" (e.g., placing a crown on a doll's head), "reiterative tasks" (e.g., stacking differently shaped blocks in a particular order) and "sequentially coordinated tasks" (e.g., creating a rapid two-tone series on a xylophone). Tasks were individually selected on the basis that the infant could not perform the target action during a pretest screening. Subjects were then assigned to either a "modeling" condition for which the target action for each task was produced twice by an experimenter or a "control" condition for which no modeling was provided, but was allowed to handle the stimuli for 10 additional seconds. Ten minutes later, all subjects were given a deferred posttest in which they were again given the stimulus materials for each task for 60 seconds. A significantly higher percent of subjects in the modeling condition produced the target action than did controls for all actions except "blocks" and "xylophone." It may be that by 12 months of age infants have had sufficient exposure to similar tasks so that the target behaviors are already in their repertoire. A significantly greater percentage of 18-month-olds than 12- 
month-olds performed all "simple/single" action tasks and "reiterative" action tasks on the post-test. There were no significant age effects for the "xylophone", one of two sequentially-coordinated actions. All subjects in control and modeling groups who did not pass the post-test were given an immediate imitation phase directly after the posttest. In this phase subjects saw the same tasks as before modeled twice and were allowed 60 seconds to reproduce each target behavior. Thus, subjects who previously served as controls during the deferred imitation test, as well as subjects in the modeling condition who failed the test, became experimental subjects for the immediate test. Fewer than 50 percent of 12 -month-old infants in the immediate imitation condition were able to imitate any of the actions, while 18-month-olds were successful at most actions. Also, there were no significant differences between experimental and control groups at either age. These results are inconsistent with those obtained by Meltzoff (1988a), which showed that 9 -month-old infants could imitate simple actions on novel objects with delays of up to 24 hours. This may be due to differences in procedures or tasks. For example, Abravanel and Gingold included only subjects who did not pass the deferred post-test and control subjects in the immediate imitation group, rather than randomly assigning new subjects for the immediate imitation group, as did 
Meltzoff. This procedure may have stacked the odds against the immediate imitation group in Abravanel and Gingold's study by sampling a nonrepresentative group of subjects who had poor imitation skills.

The literature cited above indicates that 6-month-old infants can imitate simple actions on objects and do so more readily than they imitate simple facial gestures that they cannot see themselves perform. By 9 months infants are able to imitate novel actions on objects up to 24 hours after modeling has occurred and by 12 months of age, they can imitate tasks of increasing difficulty, such as sequentially coordinated actions. Fourteen-month-olds can imitate novel actions on objects with delays of up to one week and they can delay imitation of actions on novel objects for 24 hours. These results with 14 -month-olds indicate that memory for the action and the object of that action can persist for extended periods of time. 


\section{Chapter III \\ SUMMARY OF THE LITERATURE}

The above literature review indicates that infants are capable of detecting a contingent relationship between their behavior and the subsequent occurrence of an event. Several factors contribute to an infant's ability to perceive contingencies: temporal contiguity between the infant's behavior and the contingent stimulus event, the rate, delay, and consistency with which the contingent stimulus event follows the behavior, and visual displacement of the contingent stimulus event from the infant's line of sight. Furthermore, the current literature suggests that contingency perception is tied to infants' memory capacity during initial learning. However, once a contingency is learned, infants have shown persistent memory for contingent relationships.

Two-month-olds show memory up to one day and 3-montholds up to eight days after two training sessions with a response-contingent stimulus. When given a retrieval cue, two-month-olds display memory for contingencies up to 14 days, and 3-month-olds up to 28 days. In addition, 2- and 3-month-old infants have displayed sensitivity to changes in contingent-feedback stimuli on long-term retention tests. Further, a 40 percent discrepancy in appearance between a response-contingent stimulus used during training and one 
presented to an infant on a subsequent memory test, resulted in response rates that were significantly below baseline rates. This indicates that infants encode specific information about the features of contingent stimuli.

The literature also indicates that the ability to detect and learn contingencies is present by two months of age, suggesting that infants may be predisposed to readily develop this skill. Contingency perception may thus be an ecologically adaptive ability. If so, infants may be more attuned to information about contingent events, or may be more stimulated to learn about contingent than noncontingent events. This area of perception is largely unexplored.

Much research has focused on infants' abilities to perceive contingencies. However, there is no empirical evidence regarding the subsequent memory for contingent versus noncontingent events and objects. Infants may, for example, remember contingent objects longer than noncontingent objects. If, in fact, contingent and noncontingent relationships are differentially processed or encoded, it would have several implications for the study of infant cognitive development. For example, if memory for contingency is more robust or lasts longer than memory for noncontingent events, researchers should move on to find out why. One possibility is that contingencies may be more reinforcing, may provide more information about events or 
objects or may simply be more arousing than noncontingent events or objects. This is suggested in the literature.

Several studies discussed above have shown that contingency produces a greater amount of positive affect than does noncontingent exposure to the same stimuli (Gunnar, 1980; Gunnar-Vongnechten, 1978; Lewis, Sullivan \& Brooks-Gunn, 1985; Watson \& Ramey, 1969). Also, at least one study has demonstrated that infants will engage in a contingent task longer than a noncontingent task (Lewis, Sullivan \& Brooks-Gunn, 1985).

Furthermore, teaching strategies may be modified to be more effective if contingency is found to better facilitate memory for learned behaviors. For instance, Watson, Hayes and Vietze (1982) used the principles of contingent reinforcement as intervention for a developmentally delayed infant. The subject's motor skills improved and there was evidence that she learned to discriminate instrumental contingencies after a four-month period in which the subject experienced response-contingent stimulation. This study points to a need for further investigation of responsecontingent reinforcement programs as possible treatments for developmentally delayed children.

The following research focused on infants' abilities to learn and remember the relationship between their actions and the contingent occurrence of a dynamic stimulus event. 
Differential memory for contingent versus noncontingent stimulus events was also assessed. 


\section{Chapter IV \\ METHODOLOGY}

The literature shows that infants are capable of encoding and retrieving information about contingent events (Sullivan, Rovee-Collier \& Tynes, 1979; Greco, RoveeCollier, Hayne, Griesler \& Earley, 1986 \& Davis \& RoveeCollier, 1983) and that relationships between actions and objects can be learned via imitation (Abravanel \& Gingold, 1985; Abravanel, Levan-Goldschmidt \& Stevenson, 1976; Meltzoff 1985, 1988a \& 1988d). However, there are several gaps in the contingency literature. For example, it is not known how behavior-contingent experience with a stimulus interacts with memory for the contingency. At least two questions may be asked in this regard: 1) Do infants remember objects that they can control better than objects that they cannot control, 2) Do infants show different temporal patterns of memory for objects versus actions?

Another compelling reason to study the relationship between contingency learning and memory is the potentially adaptive implications of remembering contingencies. Most infants are exposed to an array of individuals from birth. Some of those persons will be care providers and will respond contingently to the infant's solicitations for care (e.g., mom, dad, grandmother). Other individuals to whom the infant may be exposed, even on a regular basis, may not 
respond to the infants solicitations for care (e.g., an older sibling, a neighbor). It would seem beneficial for the infant to learn and remember, for example, who will feed him/her when he/she produces a 'hunger' cry. Thus, the ability to remember care providers (i.e., the providers of contingent stimulation), perhaps better than other persons not falling into this category, may prepare the infant to function more effectively in his/her environment. If so, remembering contingent relationships better than noncontingent ones may be ecologically adaptive.

Infants may be predisposed to pay more attention to stimuli that provide contingent feedback than to noncontingent stimuli. Therefore, infants who experience behavior-contingent presentations of an event may be able to retain information about that event longer than would be possible given an equal amount of noncontingent exposure to the event.

The area of contingency perception and learning by infants offers divers lines of research which may be pursued. The following research was conducted to broaden the knowledge base with regard to the relationship between infant memory and operant behavioral contingencies. The objective of the present study was to determine if there are differences in infants' memory for behavior-contingent versus noncontingent dynamic objects and for behavior- 
contingent objects versus the controlling behavior. Two research questions were addressed.

First, does having control over a dynamic object (i.e. contingency) result in longer memory for that object when compared to a non-controllable object? It was predicted that having control over a dynamic object would help infants to remember that object better than if the object were not controllable. The additional interactive property of contingency may provide another aspect of the object to be remembered. For example, in addition to remembering, "This is the object that I saw," contingent relationships may also provide the opportunity to remember, "This is the object that I turned off and on." In other words, the contingent aspect of the object may be another feature, in addition to its shape, color, size and texture, etc. that the infant can remember. Thus, contingency may function as an additional retrieval cue at the time of recall.

Another possibility is that having control over an object makes it more interesting. The infant may thus attend more to the features of contingent objects versus noncontingent objects. This may, in turn, better facilitate memory for the contingent object. However, a competing hypothesis is that not having control over a stimulus might make that stimulus more intriguing than one which can be controlled. Once the infant learns a contingent 
relationship between his/her behavior and the onset of a dynamic event, the object/source of that stimulation becomes predictable for the infant. On the other hand, objects that provide noncontingent and randomly timed stimulation are not predictable. This factor of unpredictability may make noncontingent sources of stimulation more compelling to look at for the infant. If so, infants may be more attentive to noncontingent stimuli, which may, in turn, facilitate more persistent memory for the noncontingent stimulus than for the contingent stimulus. The second research question addressed by this study was, do infants have long-term memory for the action which produces the contingent event? The conjugate reinforcement studies by Rovee-Collier and her colleagues have clearly shown that young infants show memory for the controlling behavior for at least eight days. However, in the conjugate reinforcement paradigm, the infant controls the mobile via a cord that is attached to his/her foot and the mobile. Thus, the mechanism for producing the contingent feedback connects the infant directly to the source of contingent feedback. In essence, the infant manipulates the mobile directly.

It is possible, for instance, that infants in a mobile conjugate reinforcement procedure do not realize that the cord tied to their feet functions as a manipulandum by which to move the mobile. Evidence of this is suggested by the 
phase and the familiar stimulus object was placed on the pedestal. During the action test, the familiar stimulus object was not activated, regardless of the subject's actions on the manipulanda. The test lasted for 60 seconds, beginning with the first action on either of the manipulanda. The dependent variable for this test was the proportion of target actions relative to target plus nontarget actions. Following the action test, the familiar stimulus object was removed. The reminder phase then followed.

Reminder. The beginning of the reminder phase was marked by an experimenter introducing her hands through the screen and clapping three times. The experimenter then placed the familiar stimulus object on the pedestal once again. The puxpose of this phase is to overcome possible extinction effects of the test phase on the learning of the contingency (for subjects in the contingent groups). That is, the test phase essentially exposed all subjects to the stimulus object for two minutes, during which the object could not be controlled. This could have functioned as an extinction phase for subjects in contingent groups. Thus, all subjects were given an additional 15-cumulative seconds of familiarization to the stimulus object during the reminder phase. This phase was run exactly like the familiarization phase for all subjects. The yoked procedure 
described for the familiarization phase was also employed during the reminder phase.

one-week return. The second visit to the lab consisted of a second memory for the object test, which differed from the first only in that a third stimulus served as the novel object. This was followed by a second memory for the action test, which was identical to the first. 


\section{Results}

Memory for the object

During the short-term (10 min.) novelty-familiarity preference memory test, subjects in both groups looked at the stimulus objects an average of 38.8 seconds $(S D=10.6)$ of the allotted 60 seconds during the test trials. Thus, subjects looked 65 percent of the available time to the objects. During the long-term (one week) memory test, subjects looked to the stimuli an average of 41.8 seconds $(S D=10.4)$. This was 70 percent of the available 60 seconds. A one-way ANOVA on Condition (contingent vs. noncontingent) was run on the total amount of time the subjects spent fixating the stimuli across both memory tests. This analysis revealed no significant effect of Condition $\left(\underline{\mathrm{F}}_{1,22}=0.18, \underline{\mathrm{p}}>.10\right)$.

The proportion of total looking time (PTLT) that subjects spent fixating the novel stimulus object was the used to index memory for the familiar stimulus object during the novelty-familiarity preference tests. PTLT scores reflect the average proportion of looking to the novel stimulus across the two test trials. Each subject, thus, generated two PTLT scores, one for the short-term memory test and one for the long-term memory test.

Two hypotheses were made regarding subjects' performance on this measure: 1) only subjects in contingent condition 
were predicted to show (long-term) memory for the familiar stimulus after the one-week retention interval, 2) infants in both conditions were predicted to show (short-term) memory for the familiar stimulus after the 10-minute retention interval. To test these hypotheses, a repeatedmeasures ANOVA was conducted on Condition X Time on PTLT to the novel stimulus. Although a significant condition by Time interaction was predicted, the ANOVA test indicated no significant interaction $\left(\underline{F}_{1,22}=.41, \underline{p}>.10\right)$. There was also no main effect of Condition $\left(\underline{F}_{1,22}=.73\right.$, p $\left.>.10\right)$ or Time $\left(\underline{F}_{1,22}=.22, \underline{p}>.10\right)$. Independent $t$-tests on PTLT scores, for each condition at each retention interval, against a chance level of looking (.50) also failed to yield significant results. The result of this test indicated that subjects had no preference for either the familiar or novel stimulus $\left(\underline{t}_{23}=0.667, \underline{p}>.10\right)$. Table 3 shows the means and standard deviations for subjects in both conditions across time.

The obtained results were not expected. However, if subjects demonstrated transient memory across test trials, it is possible that averaging PTLT scores across trials masked this effect. Thus, a repeated-measures ANOVA on Condition X Trials was conducted, on PTLT scores for the four trials across both tests. Again, no main effects for Condition $\left(\underline{F}_{1,22}=0.75, \underline{p}>.10\right)$ or Trial $\left(\underline{F}_{1,22}=1.03, \underline{p}>\right.$ 
.10) were found, nor was there a significant interaction $\left(\underline{F}_{1,22}=0.25, \underline{p}>.10\right)$. Separate repeated-measures ANOVA tests for each test on Condition $\mathrm{X}$ Trial also failed to reach significance.

Secondary analyses were conducted to rule out the effects of possible confounding variables. In order to determine if there was a preference for one of the three stimuli, the proportion of time the subjects spent fixating each of the three stimulus objects was calculated (across the two memory test). The mean proportion of time subjects $(\mathrm{N}=24)$ spent fixating the red, blue and yellow objects was $.56(\mathrm{SD}=.13), .49(\mathrm{SD}=.13)$ and $.46(\mathrm{SD}=.10)$ respectively. A repeated measures ANOVA on PTLT by Color indicated significant differences among these means $\underline{E}_{2,46}=$ $3.26, \mathrm{p}<.05)$. Post-hoc independent $t$-tests revealed a significant difference between the proportion of time infants fixated the red versus the yellow stimulus objects $\left(\underline{t}_{23}=2.70, \underline{\mathrm{e}}<.05\right)$. No other means differed significantly. Independent $\underline{t}$-test against a chance level of .50 was run across conditions on the proportion of time the subjects fixated the stimulus on the right for each of the object memory tests. No significant side bias was found on either the short-term memory test $\left(\underline{M}=.48, S D=.121, \underline{t}_{23}=\right.$ $0.72, \underline{\mathrm{p}}>.10)$ or the long-term memory test $(\underline{\mathrm{M}}=.51, \mathrm{SD}=$ $\left..15 \underline{t}_{23}=0.20, \underline{p}>.10\right)$. 
In summary, the analyses of the object test data failed to support the main hypotheses. Furthermore, no evidence of recognition memory was shown by the subjects on either of the two memory tests. It is unlikely that the 7.5- to 8month-old subjects were not able to recall the appearance of the familiar object. Alternative explanations for this result are discussed in Chapter 6 .

Memory for the action

The proportion of target actions (PTA) was used as the dependent variable in order to assess the subjects' preferences for the target manipulandum across each phase of the experiment (i.e., baseline, familiarization, action test 1 and action test 2). PTA scores were calculated by dividing the total number of target actions in each phase by the total number of actions on both manipulanda during that phase. A one-way ANOVA by Condition was run on baseline PTA scores to establish that there were no initial differences between the conditions. As predicted, subjects in the contingent and noncontingent groups performed similarly during the baseline phase $\left(\mathrm{F}_{1,22}=0.90, \mathrm{p}>.10\right)$. The means and standard deviations for PTA scores across phases are reported for each group in Table 4.

In order to assess contingency learning, baseline PTA scores were subtracted from familiarization PTA scores and difference scores were obtained. Only subjects in the 
contingent condition were predicted to show learning of the contingency. This hypothesis was supported by the results of independent $t$-tests on difference scores against zero. The subjects in the contingent group significantly increased the number of target actions from baseline to familiarization $(\underline{M}=.25, S D=.26, \underline{t}=3.125, \underline{\mathrm{p}}<.01)$, indicating that they learned the action-object relation. Subjects in the noncontingent group showed no increase in target actions $(\underline{M}=.00, S D=.38, \underline{t}=0.00, \underline{p}>.10)$. However, a one-way ANOVA indicated only a marginally significant difference between the group means $\left(\underline{F}_{1,22}=3.48\right.$, $\underline{p}=.08)$. This was expected given the large standard deviations in both groups.

Difference scores were calculated for PTA scores for the short-term (10 min.) and long-term (one week) action memory tests. A repeated measures ANOVA was run on Condition $\mathrm{X}$ Phase (familiarization, action test 1 and action test 2) with difference scores against baseline as the repeated dependent variable. Although group means appeared to differ (see Table 4), the standard deviations were very high, and no significant effects were found in this analysis.

Because of the variability that difference scores against baseline contributed to the data, the same analysis was conducted on PTA scores. Subjects in the contingent condition were predicted to have consistently higher PTA 
scores than subjects in the noncontingent condition. To test this hypothesis a repeated measures ANOVA was run on Condition $\mathrm{X}$ Phase on with PTA scores as the repeated dependent variable. This analysis revealed a main effect of Condition $\left(\underline{F}_{1,22}=20.25, \underline{p}<.001\right)$. There was no main effect of Phase or a condition by Phase interaction. The results of the two above analyses suggest that baseline PTA scores were highly variable, thus, the use of difference scores obscured real differences between the groups on PTA scores.

Subjects in the contingent condition were expected to demonstrate short- (10 minutes) and long-term (one week) memory for the target action as indexed PTA scores significantly above .50 during the action tests. Subjects in the noncontingent conditions were expected to demonstrate nonsignificant PTA scores across the two tests since there was no contingency for them to remember. Independent $\underline{t}$ tests against .50 supported the above hypothesis. Table 4 shows that subjects in the contingent condition maintained PTA scores significantly higher than .50 during the shortterm and long-term memory for the action tests. However, the PTA scores of subjects in the noncontingent group failed to reach significance on either test.

Independent $t$-tests were also run on difference scores in order to test if subjects maintained PTA scores above 
baseline levels. The results of these tests, also shown in Table 4, reveal that subjects in the contingent condition maintained significantly higher than baseline levels of target actions on the short-term memory test, but not on the long-term memory test. This is likely due to a large amount of variability during baseline, which is included in the difference score. Subjects in the noncontingent group showed no significant levels of target actions relative to baseline on either memory test.

Collectively, the above results indicate that there was no initial difference in PTA scores between the conditions during baseline. However, subjects in the contingent condition learned the object-action relationship during familiarization and were able to recall it 10 minutes and one week after original learning. Subjects in the noncontingent condition showed only random and nonsignificant action preferences throughout the action phases of the experiment.

Secondary analyses were conducted to rule out confounding variables. A repeated measures ANOVAs were run on Target Action $\mathrm{X}$ Phase and Target Side X Phase for PTA scores during baseline, familiarization and both memory tests to determine if subjects had a manipulandum or side (i.e., the lateral position of the target manipulandum) preference. The results of these tests revealed no main 
effects of Target Action $\left(\underline{F}_{1,22}=.00, p=.96\right)$ or Target Side $\left(\underline{F}_{1,22}=.03, p=.86\right)$. Also, ANOVAs revealed no sex differences in PTA scores across phases $\left(\underline{E}_{1,22}=.21, \mathrm{p}=\right.$ $.66)$.

\section{Interobserver Reliability}

Visual preference data. Interobserver reliability was calculated on the PTLT scores of 11 (46\% of the sample) randomly-selected subjects. A secondary observer who was unaware of the condition to which subjects were assigned observed the short-term (10 min.) memory for the object test. The proportion of total looking time subjects spent fixating the novel stimulus (PTLT) was calculated for each trial. PTLT scores derived from the observations of the secondary and primary observers were subjected to a Pearson Product-Moment correlation yielding 98 percent reliability.

Action data. The action data of the same 10 subjects was used to calculate interobserver reliability for the subjects actions on the manipulanda. A secondary observer recorded the number of actions on each of the two manipulanda throughout the experiment. The proportion of target actions (PTA) was calculated for each phase of the experiment (baseline, familiarization, action test 1 , reminder and action test 2). Pearson Product-Moment correlations were run on PTA scores derived from the observations of the secondary and primary observers for each 
phase individually and across phases. Across phases, interobserver agreement was 96 percent reliable. Correlations for individual phases range are shown in Table 5. Data from dropped and attrition subjects

Primary analyses were conducted on the memory for the object data and the memory for the action data of the 12 subjects who were dropped from the experiment. This was done to ensure that subject loss was not selective and thus did not bias the data. A repeated measures ANOVA on Condition X Time for PTLT scores failed to yield significant main effects of Condition $\left(\underline{F}_{1,10}=.31, \mathrm{p}=.59\right)$ or Time $\left(\underline{F}_{1,10}\right.$ $=.31, \underline{p}=.59)$ or an interaction $\left(\underline{E}_{1,10}=.26, \underline{p}=.62\right)$.

Means and standard deviations are reported in Table 6 .

A repeated measures ANOVA on Condition X Phase for PTA scores also failed to yield a main effect of Condition $\left(\underline{F}_{1,10}\right.$ $=1.35, \underline{p}=.27)$ or Phase $\left(\underline{F}_{1,10}=.74, \underline{p}=.57\right)$ or an interaction $\left(\underline{F}_{1,10}=.93, \underline{p}=.45\right)$. See Table 7 for means and standard deviations. The same analyses were run collapsing the data from the subjects who were dropped from the experiment with those of the final sample $(\underline{N}=36)$. Again, no significant effects were revealed. Thus, subjects who were dropped from the experiment and did not differ from the final sample with respect to visual preferences during the object memory tests or PTA scores across phases. The data generated by attrition subjects on the first 
day of testing was collapsed with that of the final sample and primary analyses were again conducted. This resulted in a group of 19 subjects in the contingent condition and 15 subjects in the noncontingent condition $(N=34)$. The data for the first object memory test were subjected to a one-way ANOVA by Condition on PTLT scores to the novel stimulus. As in the original analysis of the final sample data, no significant preferences were found. The same analysis with the data generated by attrition subjects only also revealed no significant effect. Independent t-tests against a chance level of .50 were run by condition on the combined data of the final sample and attrition subject. The results of these analyses are presented in Table 8 . No significant effects were found.

A Condition $\mathrm{X}$ Phase (familiarization and action test 1 ) repeated measures ANOVA on PTA scores revealed no significant effect of condition $\left(\underline{E}_{1,32}=2,74, \underline{p}>.05\right)$. This was inconsistent with the results of the main analyses on the final sample data. The discrepancy may have been due to the fact that the Condition $\mathrm{X}$ Phase repeated measures for final sample included three phases, whereas it was only possible to include two phases for the analysis with attrition data because infants who did not return for the second visit did not receive the second memory test. This same analysis on the data generated by attrition subjects 
only $(N=10)$ failed to yield significant results. Based on the above analyses it may be concluded that subject attrition did not contribute to the effects found in the final data sample. 


\section{Discussion}

The results of this study provide valuable and previously unavailable information about 7.5- to 8-montholds' memory for contingent versus noncontingent events. The mobile conjugate reinforcement studies have shown that 3-month-old infants can remember how to control an object for up to eight days following 18 minutes of conjugate training (Sullivan, Rovee-Collier \& Tynes, 1979). Although the present study was conducted with 7.5- to 8-month-old subjects, the paradigm employed here afforded subjects, on average, only 2.5 minutes of training. Also, the training situation in the present study required subjects to discriminate among two potential operants (i.e., two possible controlling actions). Subjects in the contingent group learned which of two actions controlled an object and they subsequently displayed long-term memory for that action one week later. These results are consistent with those of Sullivan, Rovee-Collier and Tynes (1979) and extend the findings to a different testing paradigm.

However, in the current study memory for the object itself was not evident, regardless of whether the infants controlled the object or not. Thus, there was no evidence to support the hypothesis that controllable objects would be remembered longer than uncontrollable ones. This result is somewhat inconsistent with those of Rovee-Collier, Patterson 
and Hayne (1985). Using the mobile conjugate reinforcement paradigm, these authors found that a test mobile different from the training mobile resulted in significantly decreased response rates among 2 - and 3 -month-olds 24 hours after training. This suggests that infants were able discriminate the novel mobile from the training mobile, which requires memory of the training mobile itself. Therefore, in the present study it is remarkable that 7.5 - to 8 -month-old infants showed no memory for the stimulus object either at 10 minutes or one week after training.

These results raise interesting questions regarding the effects of contingent experience on memory, as assessed by the novelty preference method, and infants' perceptions of contingency. There are three possible explanations for such findings: 1) the stimulus objects were not discriminable to the infants, 2) the infants did not remember the familiar stimulus at either 10 minutes or one week after familiarization, or 3 ) the conditions of the study did not facilitate subjects' demonstrating memory for the stimulus objects. Of the three alternatives, the third seems most likely, given the age of the subjects. There are several reasons why the conditions of the study may have contributed to the obtained anomalous results. First, perhaps interest in the nature of the object was overshadowed by the subjects' strong interest in the 
manipulanda. The presence of the manipulanda during the familiarization phase may have distracted infants from noticing the appearance of the stimulus objects, such that memory for the object was inhibited. Second, the 1-minute cumulative familiarization time that the subjects received with the familiar stimulus object may not have been sufficient to produce a significant novelty preference. Third, it may be that the effects of contingency interact with memory such that the visual preference method is not suitable for detecting infants' memory for the familiar stimulus object. Specifically, there may be a competing tendency for infants of this age to look at novel stimuli versus stimuli which they were previously able to control. Although subjects in the noncontingent condition did not control the stimulus, their actions on the manipulanda often coincided with the activation of the stimulus object. Thus, some subjects in the noncontingent group may have perceived that they controlled the stimulus even though they did not. If so, then in terms of the effect of contingency on memory, the two treatment groups did not differ. Future studies should clarify the nature of the interaction between contingency perception and memory.

The fact that infants in the contingent condition showed long-term memory for the controlling action though they failed to show memory for the object of their control is 
notable. Perhaps by 7.5 months of age infants attend more to actions, or objects that can be acted upon, rather than visual stimuli per se. Further research is needed to establish the temporal limits of action memory under the conditions of this study.

In conclusion, the research presented above raises several questions regarding the role of contingency perception in memory. Though the hypothesis that infants would remember controllable objects longer than noncontrollable objects was not supported, the results of this study are inconclusive with respect to the cause of null findings. This research also introduces a new paradigm for testing infants' memory for contingencies. 
Abravanel, E., \& Gingold, H. (1985). Learning via observation during the second year of life. Developmental Psychology, 21, 614-623.

Abravanel, E., Levan-Goldschmidt, E., \& Stevenson, M.B. (1976). Action imitation: The early phase of infancy. Child Development, 47, 1032-1044.

Cavanagh, P., \& Davidson, M.L. (1977). The secondary circular reaction and response elicitation in the operant learning of 6-month-old infants. Developmental Psychology, 13, 371-376.

Cohen, L.B., \& Gelber, E.R. (1975). Infant visual memory. In L.B. Cohen \& P. Salapatek (Eds.), Infant Perception: From Sensation to Cognition, 1, 347-403. Davis, J.M. \& Rovee-Collier, C.K. (1983). Alleviated forgetting of a learned contingency in 8-week-old infants. Developmental Psychology, 19, 535-365. Greco, C., Rovee-Collier, C., Hayne, H., Griesler, P., \& Earley, L. (1986). Ontogeny of early event memory: I. 2and 3-month-olds. Infant Behavior and Development, 9 , $441-460$.

Gunnar, M.R. (1980). Control, warning signals and distress in infancy. Developmental Psychology, 16, 281-289. Gunnar-Vongnechten, M.R. (1978) . Changing a frightening toy into a pleasant toy by allowing the infant to control 
its actions. Developmental Psychology, 14, 157-162. Hayne, H., Greco, C., Earley, L., Griesler, P. \& RoveeCollier, C. (1986). Ontogeny of early event memory: II. 2- and 3-month-olds. Infant Behavior and Development, 9 , 461-470.

Levitt, M.J. (1985). Contingent feedback, familiarization, and affect: How a stranger becomes a friend.

Developmental Psychology, 16, 425-432.

Lewis, M., Sullivan, M.W., \& Brooks-Gunn, J. (1985).

Emotional behavior during the learning of a contingency in early infancy. British Journal of Developmental Psychology, 3, 307-316.

Linde, E.V., Morrongiello, B.A., \& Rovee-Collier, C. (1985). Determinants of retention in 8 -week-old infants. Developmental Psychology, 21, 601-613.

Mason, W.A. (1978). Social experience and primate cognitive development in infancy. In M. Bekoff \& G. Burghardt (Eds.), Ontogeny of Behavior. New York: Garland.

Meltzoff, A.N. (1985). Immediate and deferred imitation in fourteen- and twenty-four-month-old infants. Child Development, 56, 62-72.

Meltzoff, A.N. (1988a). Infant imitation and memory: Ninemonth-olds in immediate and deferred tests. Child Development, 59, 217-225.

Meltzoff, A.N. (1988d). Infant imitation after a 1-week 
delay: Long-term memory for novel acts and multiple stimuli. Developmental Psychology, 24, 470-476.

Millar, W.S. (1974). The role of visual-holding cues and the simultanizing strategy in infant operant learning. British Journal of Psychology, 65, 505-518.

Millar, W.S. (1985). The effect of proximal and distal feedback on the contingency learning of 6 - and 12-monthold normal and perinatally compromised infants. Journal of Child Psychology and Psychiatry, 26, 789-800.

Millar, W.S., \& Schaffer, H.R. (1972). The influence of displaced feedback on infant operant conditioning. Journal of Experimental Child Psychology, 14, 442-453. Millar, W.S., \& Schaffer, H.R. (1973). Visual-manipulative response strategies in infant operant conditioning with spatially displaced feedback. British Journal of Psychology, 64, 545-552.

Millar, W.S., \& Watson, J.S. (1979). The effect of delayed feedback on infant learning re-examined. Child Development, 50, 747-751.

Mineka, S., Gunnar, M., \& Champoux, M. (1986). Control and early socioemotional development: infant rhesus monkeys reared in controllable versus uncontrollable environments. Child Development, 57, 1241-1256.

Reeve, L., Reeve, K.F., Brown, A.K., Brown, J.L., \& Poulson, C.L. (1992). Effects of delayed reinforcement on infant 
vocalization rate. Journal of the Experimental Analysis of Behavior, 58, 1-8.

Rovee, C.K., \& Rovee, D.T. (1969). Conjugate reinforcement of infant exploratory behavior. Journal of Experimental Child Psychology, $8,33-39$.

Rovee-Collier, C.K., \& Fagen, J. (1981). Retrieval of memory in early infancy. In L.P. Lipsitt, \& C.K. Rovee-Collier (Eds.). Advances in Infancy Research (vol. 1). Norwood, N.J. : ABLEX

Rovee-Collier, C.K., Patterson, J., \& Hayne, H. (1985).

Specificity in the reactivation of infant memory.

Developmental Psychobiology, 18, 559-574.

Sullivan, M.W., Rovee-Collier, C., \& Tynes, D. (1979). A

conditioning analysis of infant long-term memory. Child Development, 50, 152-162.

Watson, J.S. (1966). The development and generalization of

"contingency awareness" in early infancy: Some

hypotheses. Merrill-Palmer Institute, 12, 123-135 Watson, J.S. (1967). Memory and "contingency analysis" in infant learning. Merrill-Palmer Quarterly, 13, 55-76. Watson, J.S. (1971). Cognitive-perceptual development in infancy: Setting for the seventies. Merrill-Palmer Quarterly, 17, 139-152. Watson, J.S. (1972). Smiling, cooing and "the game." Merrill-Palmer Quarterly, 18, 323-329. 
Watson, J.S. (1979). Perception of contingency as a determinant of social responsiveness, In E.B. Thomas (Ed.), origins of the infants social responsiveness pp.33-63). Hillsdale, N.J.: Lawrence Erlbaum Associates. Watson, J.S., Hayes, L.A., \& Vietze, P. (1982). Responsecontingent stimulation as a treatment for developmental failure in infancy. Journal of Applied Developmental Psychology, 3, 191-203. 
Figure 1. Red, blue and yellow stimulus objects, from left to right.

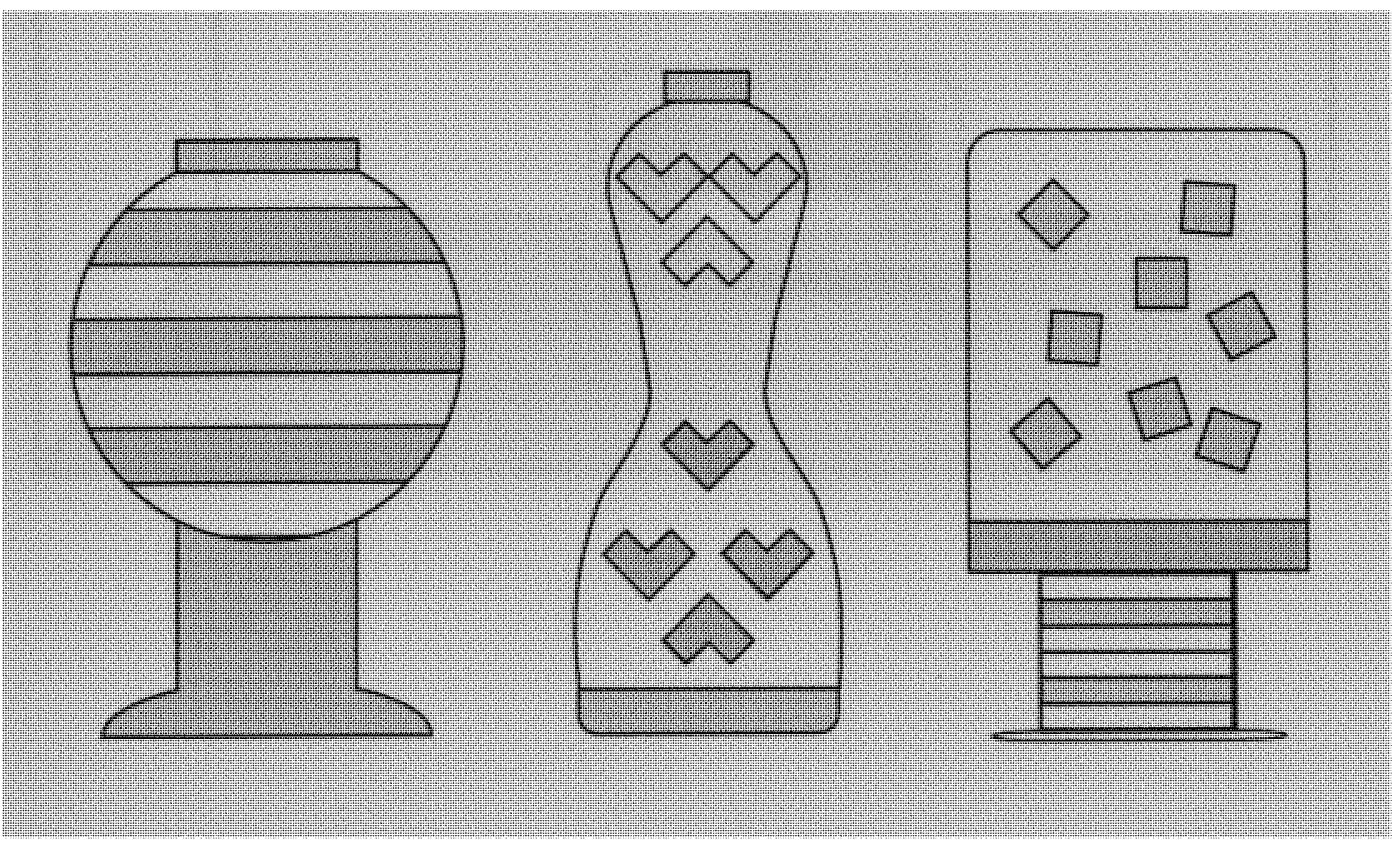


Figure 2. Apparatus from the infant's perspective.

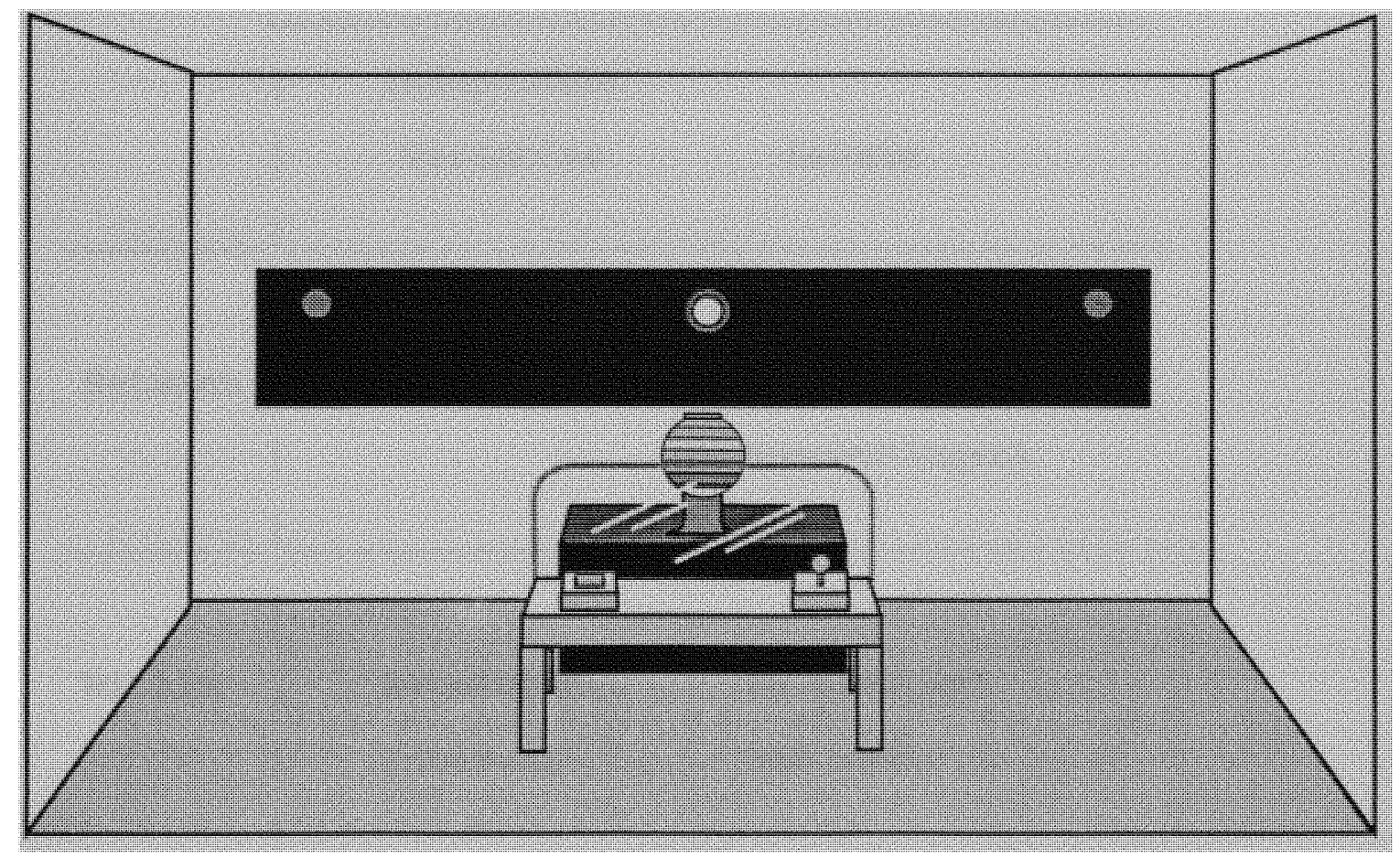


Table 1

Between- and within-subjects independent variables and levels.

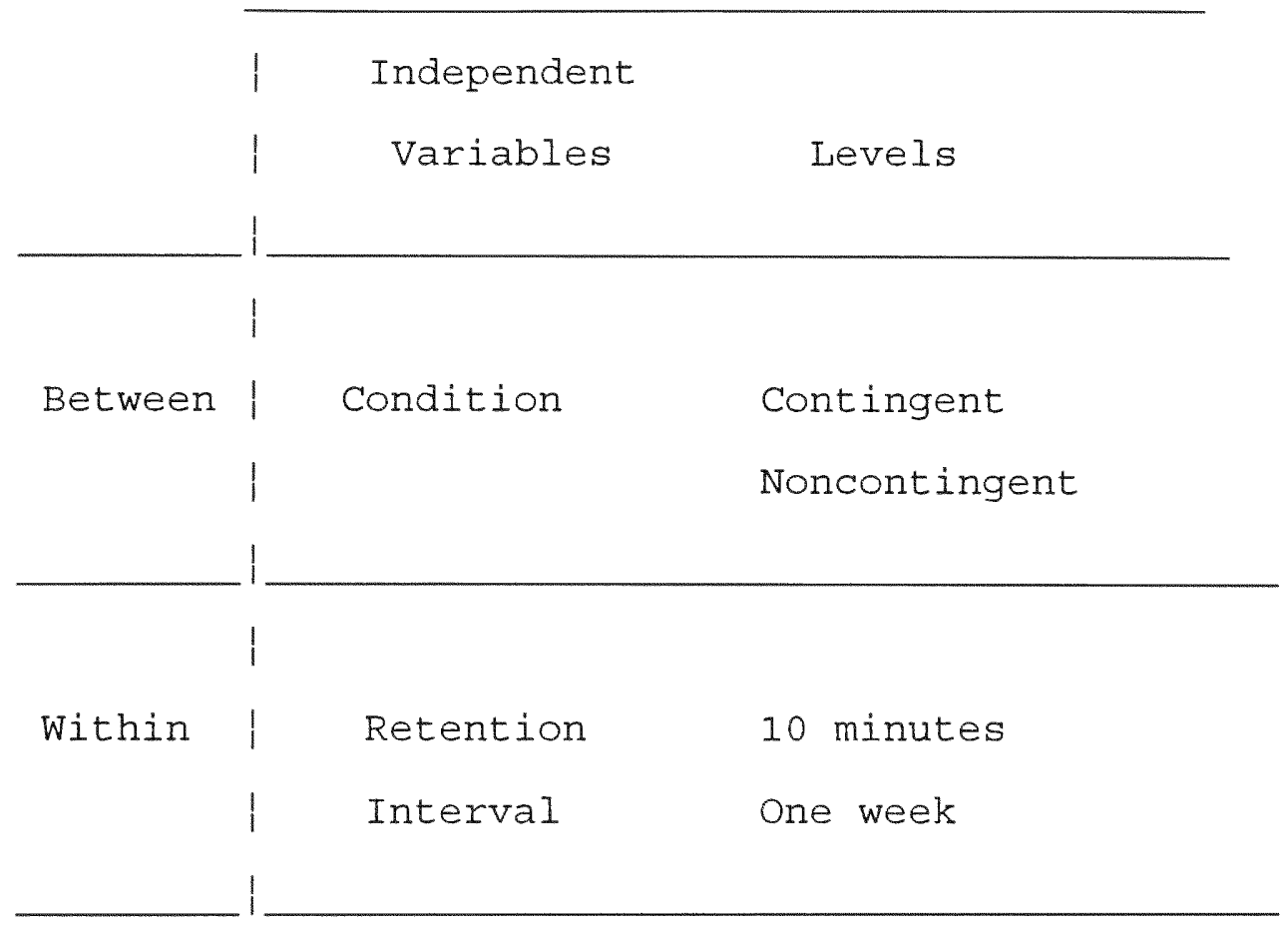


Table 2 .

Complete counterbalancing of between-subjects independent variables and levels $(\mathrm{N}=24)$.

Variable

Levels

$\mathrm{N}$

\begin{tabular}{llc}
\hline Condition & Contingent & 12 \\
& Noncontingent & 12 \\
Target & Pull Lever & 12 \\
Action & Turn Wheel & 12 \\
\hline Action & Left & 12 \\
Side & Right & 12 \\
\hline Stimulus & Red & 8 \\
\hline Object & Yellowe & 8 \\
\hline
\end{tabular}


Table 3 .

Means and standard deviations for subjects in both conditions across time $(N=24)$.

\section{Condition}

Contingent Noncontingent

\begin{tabular}{ll|l}
10 minutes & $\underline{M}=.516$ & $\underline{M}=.528$ \\
& $S D=.146$ & $S D=.145$
\end{tabular}

Time

1 week $\underline{M}=.476 \quad \underline{M}=.535$

$\mathrm{SD}=.106 \quad \mathrm{SD}=.136$ 
Table 4

ANOVA and $t$-test results for PTA and difference scores.

Condition

Phase

Baseline contingent

$$
\begin{aligned}
& .50 \\
& (.24) \\
& =0.00
\end{aligned}
$$

Familiarization

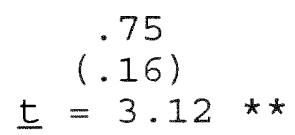
Noncontingent

$$
\begin{gathered}
(.41 \\
(.23) \\
\underline{t}=1.28
\end{gathered}
$$

Action Test 1

$$
\begin{gathered}
(.68 \\
(.20) \\
\underline{t}=2.25 \star
\end{gathered}
$$

.41

$(.28)$

$\underline{t}=1.12$

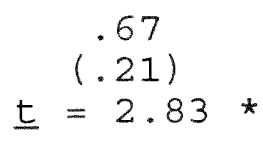

.53

(.33)

$\underline{t}=0.30$

Action Test 2

$\underline{t}=0.22$

$$
\begin{gathered}
(.17 \\
t .33) \\
=1.70
\end{gathered}
$$

$$
\begin{gathered}
(.25 \\
(.26) \\
\underline{=}=3.12 \text { * }
\end{gathered}
$$

Fam. Diff

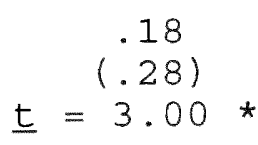

$\underline{t}=0.00$

Test 1 Diff

Test 2 Diff
.48

(.32)

.00

$(.38)$

$$
\begin{array}{r}
.12 \\
t .33) \\
=1.0
\end{array}
$$

3.02

3.48

0.19

.07

(.50)

$\underline{t}=0.50$
13.15

1.71

F

0.90

1.71

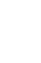


Table 6 .

PTLT scores on memory for the object tests for subjects who were dropped from the experiment $(N=12)$.

Condition

Contingent Noncontingent

\begin{tabular}{ll|l}
10 minutes $\quad \underline{M}=.512$ & $\mid \quad \underline{M}=.539$ \\
& $S D=.188$ & $\quad S D=.210$
\end{tabular}

Object test

$\begin{array}{llll} & \mathrm{n}=9 & \mathrm{n}=3 \\ 1 \text { week } & \underline{\mathrm{M}}=.498 & \underline{\mathrm{M}}=.582 \\ & \mathrm{SD}=.101 & \mathrm{SD}=.139\end{array}$


Table 5 .

Pearson product moment correlations of primary and secondary observer PTA scores across phases.

\begin{tabular}{lc} 
Phase & \multicolumn{1}{c}{} \\
\cline { 2 - 2 } Baseline & .95 \\
Familiarization & .94 \\
Action test 1 & .93 \\
Reminder & 1.0 \\
Action test 2 & .99 \\
Overall & .96
\end{tabular}


Table 8

Mean PTLT scores on the first memory for object test for the final sample and attrition subjects $(N=35)$.

\begin{tabular}{l|l}
\multicolumn{2}{c}{ Condition } \\
Contingent & Noncontingent \\
\hline $\mathrm{n}=20$ & $\mathrm{n}=15$ \\
$\underline{M}=.543$ & $\underline{M}=.481$ \\
$\mathrm{SD}=.175$ & $\mathrm{SD}=.166$ \\
$\mathrm{t}=1.11$ & $\mathrm{t}=.44$
\end{tabular}

